Rev. Adm. Saúde - Vol. 18, № 70, jan. - mar. 2018

http://dx.doi.org/10.23973/ras.70.91

ARTIGO DE REVISÃO

\title{
A relação entre a auditoria e o sistema público em saúde
}

The relationship between the audit and the public health system

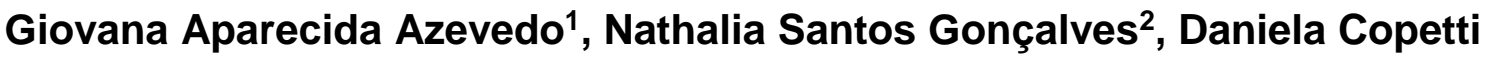 Santos ${ }^{3}$}

1. Enfermeira, especialista em auditoria em saúde. Enfermeira na Secretaria Estadual de Saúde do Estado do Rio Grande do Sul

2. Estudante de medicina pelo Instituto Meridional, Passo Fundo RS

3. Licenciada em ciências biológicas, doutora em ciências biológicas/bioquímica. Professora efetiva no Instituto Federal Farroupilha, Santa Rosa RS

\section{RESUMO}

A auditoria é percebida como ferramenta imprescindível na gestão do Sistema Único de Saúde (SUS). O objetivo no nosso trabalho foi conhecer e fundamentar os aspectos relativos à auditoria no SUS. Tendo em vista a crescente necessidade de auditoria nos serviços públicos de saúde e por ser uma atividade recente no país é necessário buscar referenciais teóricos que nos deem maior embasamento, embora exista pouca literatura sobre o tema. A pesquisa teve cunho exploratório, realizado a partir de revisão bibliográfica desde o ano de 1988 até 2016. Após análise dos dados surgiram duas questões: Definições para auditoria no SUS e recursos humanos. Entre os métodos de inclusão aqui estabelecidos os artigos deveriam ser nacionais em língua portuguesa, e publicados nos últimos anos. Foram analisados quarenta artigos referentes ao tema, porém somente cinco artigos destes falavam sobre a Auditoria no SUS. Os demais artigos conceituaram SUS e AUDITORIA em um âmbito geral. Conclui-se a partir do nosso trabalho que a auditoria é condição indispensável à gestão dos serviços públicos de saúde predominando profissionais como médicos e enfermeiros auditores, porém a profissão de auditor não está devidamente regulamentada. 
Palavras-chave: auditoria, SUS, gestão em saúde.

\begin{abstract}
Audit is perceived as an essential tool in the management of the Unified Health System (SUS). The objective in our work was to know and substantiate aspects related to the audit in SUS. In view of the growing need for auditing in public health services, and because it is a recent activity in the country, it is necessary to seek theoretical references that give us more grounding, although there is little literature on the subject. The research had an exploratory character, made from a bibliographic review from the year 1988 to 2016. After analyzing the data, two questions arose: Definitions for audit in SUS and human resources. Among the inclusion methods established here, the articles should be national in Portuguese and published in the last years. Forty articles related to this topic were analyzed, but only five of these articles were about Audit in the SUS. The other articles conceptualize SUS and AUDIT in a general scope. It is concluded from our work that auditing is an indispensable condition for the management of public health services, predominantly professionals such as doctors and nurse auditors, but the profession of auditor is not properly regulated.
\end{abstract}

Keywords: audit, SUS, health management.

\title{
INTRODUÇÃO
}

\section{Conceituando auditoria}

Atualmente a sociedade brasileira vive um período histórico de turbulência política e econômica. Nunca, medidas de fiscalização e de avaliação se fizeram tão necessárias como neste momento. Por um lado, surge a preocupação com o destino do emprego dos recursos públicos, por outro a preocupação com a qualidade dos serviços prestados, inserindo-se assim, os objetivos principais da auditoria.

O conceito de auditoria (audit) foi proposto por Lambeck em 1956 e tem como premissa a "avaliação da qualidade da atenção com base na observação direta, registro e história clínica do cliente" (1). Para Coutinho (2) "A auditoria é uma ferramenta que visa à melhoria da qualidade da gestão $e$ responsabilização da política".

Segundo o Manual de Técnico e de Orientações Básicas de Auditoria do SUS (3), do MS a auditoria consiste:

" [...] auditoria consiste no exame sistemático e independente dos fatos pela observação, medição, ensaio ou outras técnicas apropriadas de 
uma atividade, elemento ou sistema para verificar a adequação aos requisitos preconizados pelas leis e normas vigentes e determinar se as ações e seus resultados estão de acordo com as disposições planejadas. A auditoria, por meio da análise e verificação operativa, possibilita avaliar a qualidade dos processos, sistemas e serviços e a necessidade de melhoria ou de ação preventivo-corretiva / corretiva / saneadora. Tem como objetivo propiciar ao gestor do SUS informações necessárias ao exercício de um controle efetivo e contribuir para o planejamento e aperfeiçoamento das ações de saúde."

Em vários conceitos encontrados para Auditoria, relaciona-se a esta palavra o termo "Accountability". Para melhor compreensão, (4) ela é definida como aquilo que envolve principalmente transparência e responsabilização. Não que acertar seja uma obrigatoriedade, mas sim, que seja necessário se aprender com os acertos e que se aprenda assim, a melhor forma de fazer, mudando a concepção punitiva.

No setor público, onde muitos são os atores envolvidos na promoção da saúde, faz-se necessário à responsabilização pelos atos praticados, visto que os recursos são públicos, é necessário que se dê nomes a esses responsáveis.

Riolino e Kliukas (2003) ${ }^{(5)}$ referem-se que a auditoria contribui para atingir as metas estabelecidas nos princípios básicos e éticos do atual sistema público de saúde. Também procura detectar possíveis fraudes no funcionamento do SUS bem como realizar correções em possíveis distorções existentes, funcionando como mecanismo interno do Ministério da Saúde propiciando assim, o aumento da credibilidade e uma melhoria da qualidade no atendimento à saúde, fortalecendo desta forma, a cidadania.

Há várias classificações para Auditoria, para Siqueira (2014) ${ }^{(6)}$, num conceito mais amplo:
"A classificação da auditoria está sujeita a variação de acordo com a finalidade do processo, podendo ser feita de acordo com a execução (analítica ou operativa) o método (prospectiva concorrente ou retrospectiva); a forma de intervenção (interna ou externa); o tempo (contínua ou periódica); a natureza (regular ou especial); e ao limite (total ou parcial)."

Quanto às formas de operacionalização, segundo as orientações básicas de auditoria do SUS ${ }^{(3)}$, elas podem se dividir em:

Direta - Auditoria realizada com a participação de técnicos de um mesmo componente do SNA;

Integrada - Auditoria realizada com a participação de mais de um dos componentes do SNA;

Compartilhada - Auditoria realizada com a participação de técnicos do SNA, junto com os demais técnicos de outros órgãos de controle interno e externo, e estes são os tipos de auditoria. 
Elas podem ser classificadas de acordo com o tipo, em:

Conformidade - Examina a legalidade dos atos de gestão dos responsáveis sujeitos a sua jurisdição, quanto ao aspecto assistencial, contábil, financeiro, orçamentário e patrimonial

Operacional - Avalia os sistemas de saúde, observados aspectos de eficiência, eficácia e efetividade ${ }^{(3)}$.

E de acordo com a sua natureza em:

Regular ou ordinária - Ações inseridas no planejamento anual de atividades dos componentes de auditoria; e podem ser:

Especial ou extraordinária - Ações não inseridas no planejamento, realizadas para apurar denúncias ou para atender alguma demanda específica ${ }^{(3)}$.

Neste contexto a auditoria em saúde surge como um recurso imprescindível a ser empregado nas instituições públicas, entre elas, o de saúde. O objetivo deste artigo é entender como funciona a auditoria no Sistema Único de Saúde (SUS), nos três níveis de gestão: federal, estadual e municipal, tendo como referência o Sistema Nacional de Auditoria (SNA).

\section{PROCEDIMENTOS METODOLÓGICOS}

Artigo de cunho descritivo, qualitativo de pesquisa exploratória e com revisão bibliográfica buscando alcançar os objetivos propostos foi realizado a partir de artigos publicados nos bancos de dados eletrônicos: Google Acadêmico, nele compreendidos: Scientific Library Online (SciELO), Literatura Latino-Americana e do Caribe em Ciências da Saúde (LILACS), sites, assim como livros e periódicos ligados ao tema, artigos científicos nacionais, relatórios, portarias, decretos e leis disponíveis em sites governamentais publicados, entre eles os do Ministério da Saúde. Também foram encontrados artigos na Biblioteca Virtual de Saúde no período de 1988 (ano da instituição da Constituição Federal) a 2017. Sendo estes constituídos de: 3 monografias, 18 artigos, 15 sites governamentais, 1 manual de ética do COREN/RS e três livros, totalizando 40 referências.

A justificativa desse trabalho surge a partir dos profissionais da saúde que estão diretamente ligados a Secretaria Estadual de Saúde/RS. Esses profissionais diariamente estão ávidos por adquirir conhecimentos, entre eles, sobre auditoria, algo até então diferente de tudo que já haviam experimentado profissionalmente. Através desse trabalho procura-se reunir o maior número de informações possíveis, para em um futuro próximo repassá-los a todos os profissionais ligados a esse ambiente de trabalho. Para melhor organização, durante a leitura dos artigos surgiram duas principais questões norteadoras:

- Como os autores definem auditoria no SUS? 
- O que os autores trazem sobre recursos humanos na área de auditoria no SUS?

Para melhor compreensão de como funciona o processo de auditoria no SUS, faz-se necessário uma pausa para se entender a trajetória da assistência à saúde no Brasil desde o período inampsiano até os dias atuais.

$\mathrm{Na}$ análise dos dados há evidências que na visão dos autores a auditoria é condição sine qua non a gestão dos serviços públicos de saúde e com relação a recursos humanos surgiu a questão da predominância dos profissionais médicos e enfermeiros na auditoria, bem como a não regulamentação da profissão auditor.

Para responder às duas questões norteadoras foram utilizados artigos nacionais, em língua portuguesa, que fossem relacionados à auditoria no SUS. Com o objetivo de se obter uma visão mais multidisciplinar, foram analisados cinco artigos sob o enfoque de três áreas distintas, sendo estas: fisioterapia, enfermagem e odontologia. Os demais artigos foram utilizados para conceituar o SUS e AUDITORIA. As palavras-chave utilizadas estão indexadas nos Descritores em Ciências da Saúde (DeCs) são elas: auditoria, SUS, gestão em saúde.

Assim, torna-se importante salientar que em quatro dos cinco artigos selecionados, as definições referem-se à auditoria visando a qualidade dos serviços prestados pelo SUS. A auditoria no SUS surge também no enfoque dos autores como uma ferramenta atualmente imprescindível na gestão dos serviços públicos de saúde.

\section{RESULTADOS}

\section{Histórico do Sistema Único de Saúde}

Para Azevedo (2016) (7): "a assistência à saúde sempre fez parte de todas as constituições brasileiras desde o império até os dias atuais". Dos anos 60 até a promulgação da Constituição de 1988 estava configurado o regime da ditadura militar e neste período deu-se início ao processo de redemocratização do país. Ainda para este autor: "mais precisamente de 64 aos anos 80, adotou-se um arranjo federativo concentrador, sendo que o principal poder administrativo era centrado na União".

Entre os anos de 1970 e 1980, com o fim do regime da ditadura, muitos eram os problemas relativos às questões da saúde: destacava-se a desigualdade no acesso aos serviços, havia multiplicidade e descoordenação entre instituições do setor, os recursos empregados nas ações de saúde eram escassos, desorganizados e predominava a falta de resolubilidade e produtividade no emprego destes recursos e a gestão era centralizada e pouco participativa ${ }^{(8)}$.

Já na década de 80 a realidade da maioria da população brasileira era a exclusão do direito à saúde que na época era prestada pelo Instituto Nacional 
de Assistência Médica da Previdência Social (INAMPS) e tinham direito à assistência médica os trabalhadores formalmente empregados, que tinham vínculo com este instituto e assim contribuíam para o mesmo. Ao Ministério da Saúde (MS) se restringia apenas atividades de promoção da saúde e prevenção de doenças, as quais eram realizadas em caráter universal, com a assistência médico-hospitalar para poucas doenças e atendimento dos indigentes, considerados como excluídos no atendimento pelo INAMPS (7).

Conforme ilustra Weber (2004, p. 12) (9): "Aos desempregados ou aqueles à margem do processo formal de produção-emprego-renda, restavam-lhe o socorro pela solidariedade religiosa, congregadas nas Santas Casas de Misericórdia, ou, via de regra, entregues à própria sorte."

Segundo informações da Biblioteca Virtual Sérgio Arouca apud ${ }^{(7)}$ neste ínterim houve o Movimento Sanitário e em 1986 ocorreu a oitava Conferência Nacional de Saúde (CNS), evento onde a saúde foi discutida sob três principais enfoques:

a) Saúde como direito;

b) Reformulação do Sistema Nacional de Saúde e;

c) Financiamento do setor.

$\mathrm{Na}$ CNS houve consenso em torno do Sistema Único Descentralizado de Saúde (SUDS), que posteriormente se transformaria no Sistema Único de Saúde (SUS).

Assim as discussões da $8^{\underline{a}}$ CNS levaram ao reconhecimento da saúde como direito de cidadania na Constituição Federal Brasileira (CFB) de 88 que culminou com o surgimento do SUS (4):

"Este surge como um serviço de saúde para todos, onde deveria prevalecer o acesso igualitário, democrático e descentralizado. $O$ surgimento do SUS foi fundamental diante deste cenário, visto que preconiza em seus princípios e diretrizes uma política de saúde que vai de encontro a estas necessidades citadas."

Considera-se a Constituição como o marco mais importante no que se refere às transformações ocorridas no setor da saúde pública brasileira nas últimas décadas. De acordo com seu artigo 196 (10): "a saúde é direito de todos e dever do Estado, garantido mediante políticas sociais e econômicas que visem à redução do risco da doença e de outros agravos e ao acesso universal e igualitário às ações e aos serviços para a sua promoção, proteção e recuperação".

Ainda sobre a CFB, em seu artigo 197, esta ampliou os compromissos do Estado ao classificar as ações e serviços de saúde como de relevância pública e encarregando o poder público de "dispor, nos termos da lei, sobre sua regulamentação, fiscalização e controle, devendo sua execução ser feita diretamente ou através de terceiros e, também, por pessoa física ou jurídica de direito privado". 
A Lei Orgânica de Saúde de 1990, também teve papel importante nas mudanças propostas na saúde pública brasileira. "Esta dispõe sobre as condições para a promoção, proteção e recuperação da saúde, a organização e o funcionamento dos serviços correspondentes e dá outras providências" (11).

No entanto, após a aprovação do SUS e da Lei Orgânica da Saúde (1990), profundas mudanças econômicas, políticas e na esfera pública viriam a ocorrer. Em meio à crise Carlos Henrique Assunção Paiva, Luiz Antônio Teixeira, Sarney e dos que o sucederam, desfez-se o otimismo de uma rápida e radical transformação do sistema de saúde, então expresso em nossa carta constitucional. Às dificuldades em colocar em prática ações transformadoras que entravam em choque com interesses econômicos de grupos altamente organizados somava-se a complexidade do desafio representado pela implementação de um sistema único de saúde em um país com grandes disparidades regionais ${ }^{(12)}$.

"O Decreto $n^{\circ} 7508$, de 28 de junho de 2011 regulamenta a Lei $n^{\circ} 8080$, de 19 de setembro de 1990 e dispõe sobre a organização do SUS, o planejamento da saúde, a assistência à saúde e a articulação interfederativa" (3).

Este decreto, em seu artigo 20 considera:

a) a região de saúde visando características culturais, econômicas e sociais bem como redes de transportes e de meios de comunicação facilitará as ações em saúde entre estes municípios;

b) b) contrato organizativo da ação pública da saúde: são acordos facilitadores para ações em saúde;

c) a porta de entrada: facilitará o acesso inicial ao usuário do SUS;

d) comissões intergestores: são instâncias de pactuação entre entes federativos;

e) mapa da saúde: esclarece a distribuição geográfica de recursos humanos e serviços de saúde disponibilizados pelo SUS e pela iniciativa privada;

f) rede de atenção à saúde: são ações desenvolvidas em níveis de complexidade visando à integralidade na assistência em saúde;

g) serviços especiais de acesso aberto: trata-se de atendimento especial em caso de agravo ou situação laboral;

h) protocolos clínicos e diretriz terapêutica: documento a ser seguido pelos gestores que prevê diagnóstico, tratamento e acompanhamento das doenças conforme critérios pré-estabelecidos.

Com esta regulamentação é visível a preocupação com a descentralização da saúde, ou seja, quanto mais próximo o usuário estiver de sua realidade, seja ela cultural econômica ou social, provavelmente maior será a efetividade de seu tratamento e consequentemente, menores serão os custos envolvidos. 
Na prática, surge no estudo de Azevedo (2016) ${ }^{(7)}$ um artigo sobre Tratamento Fora do Domicílio (TFD) no estado do Piauí, contemplando um dos princípios do SUS, a universalidade, este instrumento legal visa proporcionar através do custeio de passagens e diárias o acesso dos pacientes ao tratamento de enfermidades não existentes nas localidades em que residem.

Conforme o ABC do SUS, o SUS trata-se de um sistema porque significa que é um conjunto de unidades, de serviços e ações que têm um objetivo em comum: a promoção, proteção e recuperação da saúde. Único porque deve seguir a mesma doutrina e os mesmos princípios organizativos em todos os estados brasileiros, sob a responsabilidade das três esferas de governos: federal, estadual e municipal. Conforme a lei Orgânica o SUS "é uma nova formulação política e organizacional para o reordenamento dos serviços e ações de saúde estabelecida pela CFB de 1988" (13).

Com uma população superior a 200 milhões de habitantes o Brasil tem, como uma das tarefas mais difíceis e complexas garantir o acesso aos serviços de saúde de forma integral, igualitário e gratuito, direito esse garantido na CFB ${ }^{(14)}$.

Assim sendo, o SUS hoje é um dos maiores sistemas públicos de saúde do mundo, abrange desde atendimentos ambulatoriais até transplantes de órgãos, garantindo acesso de forma integral, universal e gratuita para toda a população do país ${ }^{(15)}$. Esse sistema (16) "nasceu da luta de diversos atores sociais por inclusão social, democracia e construção de uma consciência cidadã a partir da compreensão de direitos e deveres de solidariedade". Além dos princípios e diretrizes do SUS já observados na CFB, como a universalidade, equidade, integralidade foi fundamental a participação da comunidade sendo que para isto foram criados os Conselhos e as Conferências de Saúde. Alguns pesquisadores questionam sobre a supremacia e organização destas entidades, pois acreditam que existam dificuldades em se contemplar a diversidade nas opiniões de toda a sociedade nestes espaços.

Conforme ilustra Feijão et al (2015, p. 9) ${ }^{(8)}$ :

"Uma das grandes conquistas alcançadas com a consolidação do SUS foi a inserção da participação social entre seus princípios basilares, possibilitando a atuação da população na formulação e fiscalização das políticas e ações públicas de saúde, por intermédio de mecanismos de representação social, como os conselhos e as conferências de saúde."

Nos Conselhos de Saúde, os gestores, servidores, presidentes de associações bem como representantes da comunidade podem atuar tanto na formulação e desenvolvimento de políticas públicas de saúde, como também na fiscalização das mesmas ${ }^{(17)}$.

Fazem parte do SUS os seguintes conselhos: Conselho Nacional de Saúde (CNS), Conselho Nacional das Secretarias de Saúde (CONASS) e Conselho Nacional das Secretarias Municipais de Saúde (CONASEMS). Sendo que as conferências de saúde ocorrem a cada quatro anos, convocadas pelo poder executivo, em cada esfera de governo, servindo como espaço de debates sobre a saúde ${ }^{(17)}$. 
"Porém, passadas aproximadamente duas décadas de sua instituição, o SUS ainda não conseguiu alcançar os reais objetivos de seus princípios e diretrizes e efetivar os direitos à saúde pela população. A concretização destes princípios ainda produz intensas discussões" (18).

Uma delas é a forma como ocorre o financiamento do SUS e a outra é como fazer o uso adequado dos recursos provenientes deste financiamento.

Certamente a auditoria no SUS veio como recurso importante para a melhoria da aplicação destes recursos.

\title{
Auditoria no sus: o que é, para que serve e como funciona
}

Para Feijão (2015, p. 67) ${ }^{(8)}$ :

\begin{abstract}
"[...] a operacionalização dos processos de trabalho em auditoria se desenvolve em três fases - analítica operativa e relatório - e segue uma rotina padronizada, independentemente do foco ou objeto da auditoria, podendo originar-se do planejamento anual do serviço ou de demandas não programadas."
\end{abstract}

Segundo Motta, Leão e Zagatto (2005) (19) a auditoria no Brasil, antes de instituir-se o SUS, estava vinculada ao INAMPS e não chegou a ser devidamente descentralizada sendo que sua estrutura apresentava um alto grau de burocracia que conservou sua forma de funcionamento, não chegando à construção de uma "cultura estadual".

Sendo assim, o processo de trabalho de auditoria é sempre o mesmo, o que muda é o seu objeto de trabalho, sendo que os objetos de trabalho de auditoria do SUS são basicamente os seguintes: a) as ações de saúde, sejam elas programáticas ou pontuais, por exemplo: atendimentos específicos, entre outras; b) os serviços de saúde, sejam eles ambulatoriais, hospitalares, laboratoriais, exames de imagem, alto custo, entre outros e c) os sistemas de saúde das três esferas de governo ${ }^{(8)}$.

A auditoria em saúde tem como objetivo maior, melhorar a qualidade do atendimento ao paciente. Tem sua origem no Reino Unido, sendo idealizada por profissionais médicos que buscavam proporcionar um atendimento de melhor qualidade à clientela, chamando a atenção para as deficiências na prestação de cuidados, na tentativa de frear a prática ineficiente e ineficaz (20).

A auditoria tem um papel de destaque no processo de consolidação do SUS. A auditoria pública procura analisar o funcionamento do SUS para evitar possíveis fraudes ou realizar correções nas distorções existentes, além de verificar a qualidade da assistência e o acesso dos usuários às ações e serviços de saúde. Funciona também como um mecanismo de controle interno do Ministério da Saúde (MS); propiciando, desta forma, um aumento da credibilidade e uma melhoria na qualidade da atenção à saúde, fortalecendo a cidadania (21). 
A finalidade da auditoria é contribuir com a gestão para a qualificação do acesso universal, em prol da garantia do direito à saúde e do direito à vida, definidos na CFB de 1988, sendo o relatório de auditoria um produto relevante, um instrumento informativo e construtivo, de alta credibilidade pública. $\mathrm{O}$ produto da auditoria é reconhecidamente imprescindível na tomada de decisões ${ }^{(8)}$.

Para Moimaz et al., (2012) (22) "é importante o sistema de auditoria como um instrumento confiável aos gestores no planejamento e avaliação das ações em saúde".

As práticas de auditoria já fazem parte da gestão administrativa de muitas instituições hospitalares, que tentam moldar seu processo de trabalho de forma a facilitar futuras intervenções, como é o caso do Hospital de Clínicas de Porto Alegre, onde se realizam auditorias a partir dos documentos informatizados, objetivando com isto, a melhoria da qualidade dos registros e do cuidado, uma vez que a auditoria quantitativa dos registros foi facilitada pela utilização da ferramenta informatizada ${ }^{(23)}$.

Na trajetória diária dos serviços públicos de saúde, percebe-se que, no que tange à participação democrática e popular há avanços, porém, as dificuldades no acesso aos serviços de saúde ainda são muitos, como será relatado no decorrer deste estudo.

Devido à magnitude territorial do Brasil, o SUS teve muitas dificuldades em sua implementação ${ }^{(7)}$ : "O acesso universal e igualitário estabelecido como princípio do SUS vem sendo estabelecido de forma gradual em função da complexidade decorrente das enormes diferenças regionais e da pluralidade de contextos vivenciados pelos municípios brasileiros."

\section{Financiamento do SUS}

No Brasil, a implantação de processos de auditoria no SUS procura resguardar ao usuário e a União, estados e municípios a qualidade dos serviços profissionais e institucionais além de preservar o uso adequado do dinheiro público. A Lei n. 8.080, de 19 de setembro de 1990 (13), ao regular as ações e os serviços de saúde em todo o território nacional, estabelece o Sistema Nacional de Auditoria (SNA) como um mecanismo de controle técnico e financeiro, sob competência do SUS e em cooperação com os estados, Distrito Federal e municípios. No entanto, a instituição desse sistema deu-se apenas em 27 de julho de 1993, pela Lei Federal n. 8.689 em seu art. 6o (24), e sua regulamentação ocorreu pelo Decreto n. 1.651 de 28 de setembro de1995 (25).

Nesse decreto ${ }^{(21,25)}$ pode-se observar as competências do SNA nas três esferas governamentais, sendo identificada, a nível federal, a aplicação dos recursos transferidos aos estados e municípios, as ações e serviços de saúde de abrangência nacional, os sistemas estaduais de saúde e suas ações, métodos e instrumentos colocados em prática para controle, avaliação e auditoria. 
A nível estadual observa-se a utilização dos recursos transferidos aos municípios; as ações e serviços previstos no plano estadual de saúde; os servidores de saúde sob sua gestão, sendo estes públicos ou privados, contratados ou conveniados; os sistemas municipais de saúde e seus consórcios intermunicipais e as ações, métodos e instrumentos executados pelos órgãos municipais de controle, avaliação e auditoria.

A nível municipal são observadas as ações e os serviços estabelecidos no plano municipal de saúde, os servidores de saúde sob sua gestão, sejam públicos ou privados, contratados e conveniados, e as ações e serviços desenvolvidos por consórcio intermunicipal ao qual o município esteja vinculado.

A nível federal, as ações são desenvolvidas pelo DENASUS, enquanto que nos estados e municípios, são executadas por suas áreas de controle, avaliação e auditoria inseridas conforme respectivas secretarias de saúde.

O financiamento é sabidamente um dos pontos mais importantes para a consolidação e sucesso de políticas públicas, entre elas o SUS. Muito tem sido discutido sobre a necessidade de financiamento específico, definido e definitivo para saúde, o que tem sido preconizado através da devida execução da Emenda Constitucional 29 por parte das diferentes esferas de gestão do SUS (26).

A regulamentação da Lei no 141/2012 em seu inciso 3으 do Art.198 da Constituição Federal estipula uma quantia mínima a ser aplicada anualmente pela União nas ações em saúde (27):

"Estes percentuais das receitas fiscais são de 15\% (nível municipal), $12 \%$ (nível estadual) e ao valor do ano anterior, acrescido da correção do PIB (União), sendo que o controle sobre a utilização destes recursos será realizado pelos Conselhos de Saúde, exceto os de controle específico do SUS, o SNA (27)."

A Lei $8.080(1990)^{(11)}$ em seu art. 33 prevê que os recursos financeiros do SUS serão depositados em conta especial, em cada esfera de sua atuação, e movimentados sob fiscalização dos respectivos Conselhos de Saúde, sendo que no âmbito federal, estes recursos oriundos do Orçamento da Seguridade Social, serão administrados pelo Ministério da Saúde, por intermédio do Fundo Nacional de Saúde (FNS) ${ }^{(11)}$ :

"O Ministério da Saúde acompanhará, através de seu sistema de auditoria, a conformidade à programação aprovada da aplicação dos recursos repassados a Estados e Municípios. Constatada a malversação, desvio ou não aplicação dos recursos, caberá ao Ministério da Saúde aplicar as medidas previstas em lei (11)."

A alocação adequada dos recursos financeiros proporciona uma satisfação das demandas e das necessidades da coletividade no âmbito do SUS (22): os relatórios resultantes das auditorias são instrumentos que servem de parâmetros para reformulação de trabalhos efetuados, diretrizes de controle e 
avaliação do serviço. Podem servir também como um norteador de como proceder no faturamento de procedimentos feitos pelo SUS, evitando perdas financeiras e de indicadores de saúde, servindo também como papel educativo e ilustrativo por meio de recomendações de melhorias futuras nos serviços, diminuindo os maiores impactos relativos à gestão.

O cumprimento dos princípios do SUS - universalidade, integralidade e equidade e está intrinsecamente relacionado à missão do SNA e sua importância consiste em fiscalizar o desenvolvimento de ações e serviços ofertados pelo SUS, corrigindo falhas existentes e atendendo assim, a população da melhor maneira possível (28).

Dentro dessa perspectiva, o Departamento Geral de Ouvidoria do SUS (DOGES) e o Departamento Nacional de Auditoria do SUS (DENASUS) da SGEP/MS possuem papel fundamental para o fortalecimento da gestão estratégica e participativa, qualificando os processos de gestão do SUS ao ouvir, analisar e encaminhar as demandas provenientes dos usuários, além de auditar as contas do SUS de forma pública e transparente ${ }^{(8)}$.

No estudo a seguir surge a questão de que o contato com o usuário do SUS visando sua opinião sobre os serviços é fato:

"Na auditoria do SUS o contato com o usuário é frequente. Ressaltamos a importância desta conduta em tomar a opinião do usuário como referência, valorizando a sua percepção e permitindo o cruzamento dos dados obtidos com as outras fontes de informação. Desta forma, o processo de análise da auditoria é feito com base não somente no cumprimento das leis e regras estabelecidas no SUS, mas também com a visão de quem utiliza estes serviços ${ }^{(29) . "}$

"O DENASUS realiza auditoria e fiscalização no SUS, de forma preventiva e operacional, comparando as situações encontradas com um determinado parâmetro técnico, operacional ou legal, além disso, avalia se as atividades vinculadas ao SUS estão sendo realizadas segundo critérios de eficácia, eficiência e efetividade e também orienta os gestores com relação ao uso adequado dos recursos destinados à saúde (14)."

As competências do DENASUS estão descritas no artigo 35 do Decreto № 7.797 de 2012. Em resumo, o artigo apresenta as competências do DENASUS como as de promover o fortalecimento do SNA do SUS; auditar a adequação, a qualidade e a efetividade das ações e serviços públicos de saúde, e a regularidade legal das aplicações dos recursos do SUS; estabelecer e propor diretrizes e normas para a padronização das ações de auditoria; integrar as ações e procedimentos de auditoria do SNA do SUS; e, demais atividades inerentes ${ }^{(30)}$.

Quanto às atividades planejadas pelo DENASUS, estas podem ser demandadas pelo Ministério da Saúde ou pelos órgãos de controle, como Controladoria Geral da União, Tribunal de Contas da União, Ministério Público, 
Polícia Federal, Poder Legislativo, por solicitação dos cidadãos, por meio de denúncias ou até mesmo por reclamações à Ouvidoria Geral do SUS ${ }^{(14)}$.

Em BRASIL (2011) ${ }^{(3)}$ consta que:

"[...] na SGEP, a auditoria assume o significado de instrumento de gestão que fortalece o SUS, contribuindo para a alocação e utilização adequada dos recursos, a garantia do acesso e a qualidade da atenção à saúde contribuindo para a alocação e utilização adequada dos recursos, a garantia do acesso e a qualidade da atenção à saúde oferecida aos cidadãos. Esta concepção altera a lógica incorporando a preocupação com o acompanhamento das ações e análise dos resultados."

\section{A auditoria e o profissional de saúde auditor}

Sobre o profissional auditor, alguns pesquisadores ${ }^{(31)}$, referem que este não deve exercer ou elaborar atividades as quais audita. Por outro lado, não deve ter sequer alguma relação de dependência com as mesmas, assim, manter esta independência viria a facilitar o exercício de suas funções e os resultados de suas auditorias seriam mais imparciais e sem comprometimento já que para exercer a função de auditor é necessária cautela, pois, ao estar subordinado às necessidades da alta administração, precisa se tornar subserviente à política vigente, o que pode vir a comprometer o princípio da isenção. Logo, essa independência se obtém através da posição que o auditor ocupa e da sua objetividade.

Ainda sobre o auditor, "a auditoria não se resume, apenas, em controle contábil. Exige um olhar atento à universalidade do problema em foco, demandando dos auditores uma boa formação e dos gestores de auditoria a composição de equipes multidisciplinares" (8). Porém sabe-se que a disponibilidade de recursos humanos nesta área é escassa.

O processo de trabalho na auditoria do SUS tem sido desempenhado por equipes multiprofissionais, em que médicos, enfermeiros, nutricionistas, odontólogos e farmacêuticos já conquistaram seu espaço e desempenham suas funções mediante integração de conhecimentos e experiências, porém, quase não dispõe de fisioterapeutas auditores, assim os serviços de fisioterapia acabam por ser auditados por profissionais não especializados, o que certamente fragiliza as auditorias específicas desta área $(29,32,33)$. O ideal seria que cada área fosse auditada por um profissional específico, por exemplo: os serviços odontológicos por um odontólogo, os de farmácia por um farmacêutico e assim respectivamente.

O serviço de auditoria deste sistema de saúde, de direito nunca existiu, mas sim a figuração de profissionais médicos que desempenhavam as funções de autorização de internação hospitalar e revisão de contas médicas, comumente confundida como sendo atividades de auditoria, por conta da incapacidade ou mesmo impossibilidade de compreensão da significação das ações de auditoria 
para própria gestão do sistema e, da quase exclusividade desta modalidade de assistência, pela característica intrínseca do sistema vigente, hospitalocêntrico (9).

$\mathrm{Na}$ Lei 7.498/86 em seu art. 11, item H é nítido que os serviços de consultoria, auditoria e emissão de parecer sobre matéria de enfermagem são privativos do enfermeiro.

Algumas pesquisas ${ }^{(29)}$ referindo-se à atuação das enfermeiras auditoras, colocam que embora haja um discurso de que a auditoria tem como principal objetivo, a qualidade dos serviços prestados na realidade o principal objetivo de seu trabalho é a redução de custos e que estas profissionais entrevistadas tentam passar a ideia da preocupação com a qualidade já que sua formação visa o cuidado. Referem também que as mesmas não têm total autonomia ficando sob a vontade de seus gestores como surge no seguinte relato:

"Nos discursos, as enfermeiras tentam negar a finalidade do controle
financeiro de sua prática, buscando demonstrar que esse é um objetivo
secundário e que a preocupação com a qualidade do atendimento é a
prioridade da auditoria. No entanto, esse parece ser um ideal sustentado
por algumas das entrevistadas, pois ao descreverem o dia-a-dia de sua
prática, fica evidente que suas ações não se dirigem para esse fim.
Admitir que sua prática é voltada para o controle financeiro pode ser
desconfortável para profissionais que tem a sua formação voltada para o
cuidar e uma prática que carrega, historicamente, a marca do servir (29)."

Hoje, através de uma proposta educativa permanente, há uma grande preocupação por parte do DENASUS, com a qualificação das práticas existentes nos órgãos responsáveis pela auditoria no SUS. Torna-se necessário que estas práticas estejam alinhadas com os princípios do SUS. O DENASUS exerce atividades de auditoria e fiscalização especializadas no âmbito do SUS, constante na Política Nacional de Gestão Estratégica e Participativa do SUS (Participa SUS) ${ }^{(14)}$. A partir da análise feita nessa pesquisa surgiu a questão da predominância do médico e do enfermeiro atuando na função de auditor em saúde e também a situação não regularizada da profissão auditor em saúde.

\section{CONSIDERAÇÕES FINAIS}

Vários foram os achados durante a leitura dos artigos: fica claro que a inserção da participação do cidadão tanto na construção das políticas de saúde é fato, bem como no financiamento do SUS. Também surgiram as questões da não regulamentação da profissão auditor, da predominância dos profissionais médicos e enfermeiros como auditores, em detrimento de outras áreas de atuação, indo à contraposição ao que prevê o SNA que salienta a necessidade de equipes multidisciplinares nas auditorias.

A auditoria é entendida por todos os autores como uma ferramenta realmente imprescindível na gestão de saúde pública, mas sua efetivação e 
descentralização ainda estão em andamento. Por outro lado, a auditoria no SUS, na visão dos autores, deixa de ter um olhar punitivo para dar lugar a uma ótica educativa. Num outro enfoque, a auditoria em saúde gradativamente muda seu vínculo ligado as questões financeiras e de diminuição de custos para também fazer parte da qualidade dos serviços de saúde.

Muitos são os avanços no que se refere à democratização do SUS e nas medidas avaliadoras e de fiscalização do setor público de saúde, e a consequência destes atos fez surgir os serviços de auditoria no sistema público de saúde, porém se remetermo-nos aos motivos que levaram à criação do SUS iremos perceber que a maioria dos problemas ainda persistem. Percebe-se que em termos de auditoria no SUS, há muita escassez na literatura, sobre o assunto. É preciso que mais estudos sejam feitos, e o emprego de capacitações adequadas às pessoas envolvidas, juntamente com "accountability", responsabilizando assim os sujeitos. Possivelmente, desta forma os princípios e diretrizes do SUS, possam realmente estar alinhados com os objetivos da auditoria. No momento em que a legislação (teoria), se adequar à prática (vivência diária), certamente a saúde pública brasileira será de excelência.

No decorrer deste estudo surgiram diversos conceitos para definir auditoria. $O$ que melhor aplicou-se à realidade foi que a auditoria trabalha para qualificar a gestão do SUS, implicando diretamente na melhoria do acesso às ações e serviços de saúde pela população, contribuindo para atender aos seus princípios básicos: universalidade, integralidade e equidade. Ainda para esta autora, o principal desafio do SUS é oferecer um serviço de qualidade associado ao baixo custo à imensa população brasileira que busca diariamente na rede dos serviços públicos de saúde um atendimento digno (21).

Concluiu-se através deste estudo que a auditoria não é somente associada a custos, a mesma pode ser utilizada para gerir a qualidade e as melhorias dos processos dos trabalhos em saúde facilitando o trabalho dos profissionais desta área e por consequências dos seus pacientes.

\section{REFERÊNCIAS}

1. Caleman G, Moreira ML, Sanchez MC. Auditoria, Controle e Programação de Serviços de Saúde. Faculdade de Saúde Pública da Universidade de São Paulo. São Paulo, 1998. Disponível em:

http://bvsms.saude.gov.br/bvs/publicacoes/saude_cidadania_volume05.pdf.

2. Coutinho BM. Auditoria do Sistema Único de Saúde: um estudo de caso do Componente Estadual de Auditoria de Pernambuco (CEA/SUS/PE. 2014. Disponível em:<https://scholar.google.com.br/scholarhl=ptBR\&q=Auditoria+do+Sistema+Ú nico+de+Saúde+um+estudo+de+caso+do+Componente+Estadual+de+Auditori a+de+Pernambuco(CEA/SUS/PE\&btnG;=\&lr;=>. 
3. Brasil. Ministério da Saúde. Secretaria de Gestão Estratégica e gestão Participativa. Sistema Nacional de auditoria. Sistema Nacional de auditoria no SUS. Auditoria do SUS: orientações básicas. Brasília: Ministério da Saúde, 2011. http://sna.saude.gov.br/download/LivroAuditoriaSUS_14x21 cm.pdf

4. Brasil. Tribunal de Contas da União. Referencial para avaliação de governança em políticas públicas. Tribunal de Contas da União. Brasília, 2014. https://portal.tcu.gov.br/biblioteca-digital/referencial-para-avaliacao-degovernanca-em-politicas-publicas.htm

5. Riolino AN, Kliukas GBV. Relato de experiência de enfermeiras no campo de auditoria de prontuário: uma ação inovadora. Nursing 65(6):35-8, 2003.

6. Siqueira PLF. Auditoria em Saúde e Atribuições do Enfermeiro Auditor. 2014. Disponível em:

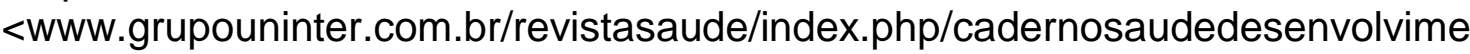
nto/article/viewfile/303/234>.

7. Azevêdo SR. O Programa de Tratamento Fora de Domicílio no Sistema Único de Saúde no Piauí. Holos, [s.l.], v. 2, p.402-413, 20 abr. 2016. Instituto Federal de Educação, Ciência e Tecnologia do Rio Grande do Norte (IFRN). DOI: http://dx.doi.org/10.15628/holos.2016.3360.

8. Feijão AMM, Salazar F, Moro MFSA, Souza RMP. Curso Nacional de Qualificação de Auditorias e Ouvidorias do SUS, Qualificação de Auditorias e Ouvidorias: fortalecimento de áreas estratégicas do SUS. 2ª ed. Rio de Janeiro. Fiocruz, 2015. Disponível em:http://rededeescolas.ensp.fiocruz.br/sites/default/files/Curso_Nacional_de Qualificacao_de_Auditorias_e_Ouvidorias_do_SUS-AUDITORIA__2aEdicao.pdf Acesso em: 22 de fev. de $201 \overline{ }$.

9. Weber CAT. O Papel da Auditoria no SUS. 40 f. TCC (Graduação) - Curso de Administração, Universidade Federal do Rio Grande do Sul, Porto Alegre, 2004. Disponível em:

https://www.lume.ufrgs.br/bitstream/handle/10183/103893/000427280.pdf?sequ ence=1 Acesso em: 20 de jan. 2018.

10. Brasil. Ministério da Saúde. Constituição. Constituição da República Federativa do Brasil. Brasília, DF: Senado, 1988. Disponível em: http://www.senado.leg.br/atividade/const/con1988/CON1988_05.10.1988/ind.as p Acesso em: 02 de fev de 2018.

11. Brasil. Presidência da República. Casa Civil. Subchefia para assuntos jurídicos. Dispõe sobre a Lei n. 8.080 de 19 de setembro de 1990. Brasília: 1990. Disponível em: http://www.planalto.gov.br/ccivil_03/leis//8080.htm Acesso em: 02 de fev de 2018.

12. Paiva CHA, Teixeira LA, Reforma Sanitária e a criação do Sistema Único de Saúde: notas sobre contextos e autores. História, Ciências, Saúde. v.21, n.1, jan.-mar., p.15-35, Rio de Janeiro, 2014. DOI:

http://dx.doi.org/10.1590/S0104-59702014000100002 
13. Brasil. Ministério da Saúde. Secretaria Nacional de Assistência à Saúde. ABC do SUS: Doutrinas e Princípios, 1990. Disponível em:

<http://www.pbh.gov.br/smsa/bibliografia/abc_do_sus_doutrinas_e_principios.p df>. Acesso em: 14 mar. 2017.

14. Brasil. Ministério da Saúde. Conheça o Departamento. 2015. Disponível em: <http://portalsaude.saude.gov.br/index.php/o-

ministerio/principal/secretarias/545-sgep raiz/denasus/19901-conheca-odepartamento>. Acesso em: 28 nov 2016.

15. Brasil. Ministério da Saúde. Cartilha do Servidor. Brasília-DF, 2009.

Disponível em:

http://bvsms.saude.gov.br/bvs/publicacoes/cartilha_servidor_p1.pdf Acesso em: 22 fev 2018.

16. Brasil. Ministério da Saúde. Secretaria de Gestão Estratégica e

Participativa. Conass. Conselho Nacional de Secretarias Municipais de Saúde. Prêmio Sérgio Arouca de Gestão Participativa no SUS: experiências exitosas e artigos acadêmicos/Ministério da Saúde. Brasília: 2010. 144 p. Disponível em: http://bvsms.saude.gov.br/bvs/publicacoes/premio_sergio_arouca_experiencias _exitosas.pdf Acesso em: 15 jan. 2018.

17. Brasil. Ministério da Saúde. Conselho Nacional de Saúde. Conselhos de saúde: a responsabilidade do controle social democrático do SUS. 2013.

Disponível em:

<http://bvsms.saude.gov.br/bvs/publicacoes/conselhos_saude_responsabilidad e_controle_2edicao.pdf>. Acesso em: 14 mar. 2017.

18. Yahn PIFC, Yasui S. O apoiador caipira: o desafio/arte de articular redes regionais a partir de territórios desejos singulares. 2014. Disponível em:

<http://www.scielo.br/pdf/icse/v18s1/1807-5762-icse-18-1-0871.pdfm>. Acesso em: 16 jul. 2017.

19. Motta ALC, Leão E, Zagatto JR. Auditoria médica no sistema privado: abordagem prática para organizações de saúde. São Paulo: Látria; 2005.

20. Rosa VL. Evolução da Auditoria no Brasil. Monografia (Especialização em Auditoria em Saúde) - Centro Universitário Filadélfia - UniFil, Londrina-PR., 32 f. 2012. Disponível em:

http://web.unifil.br/pergamum/vinculos/000007/000007B1.pdf Acesso em: 02 fev 2018.

21. Santos CA, Santana EJS, Vieira RP, Garcia EG, Trippo KV. A Auditoria e o Enfermeiro como Ferramentas de Aperfeiçoamento do SUS. Revista Baiana de Saúde Pública, v.36, n.2, p.539-559 abr./jun. 2012. Disponível em:

http://files.bvs.br/upload/S/0100-0233/2012/v36n2/a3254.pdf Acesso em: 02 fev 2018.

22. Moimaz SAS, Ayach C, Garbin CAS. Auditoria na Saúde: justificativas de glosas no setor odontológico. Araçatuba: Universidade Estadual Paulista.

Health Sci Inst, 30(2):112-6, 2012. Disponível em: 
https://www.researchgate.net/publication/284029484_Auditoria_na_Saude_justi ficativas_de_glosas_no_setor_odontologico Acesso em: 22 fev 2018.

23. Almeida MA et al. 2) Processo de Enfermagem na prática clínica: estudos clínicos realizados no Hospital de Clínicas de Porto Alegre. Porto Alegre: Artmed, 319 p., 2011.

24. Brasil. Presidência da República. Casa Civil. Subchefia para Assuntos Jurídicos. Lei n 8.689, de 27 de julho de 1993. Dispõe sobre a extinção do Instituto Nacional de Assistência Médica da Previdência Social (Inamps) e dá outras providências. Brasília: 1993. Disponível em:

http://www.planalto.gov.br/ccivil_03/leis/L8689.htm Acesso em: 20 fev 2018.

25 . Decreto $\mathrm{n} 1.651$, de 28 de setembro de 1995. Regulamenta o

Sistema Nacional de Auditoria no âmbito do Sistema Único de Saúde.

Disponível em: http://www.planalto.gov.br/ccivil_03/decreto/1995/d1651.htm Acesso em 20 fev 2018.

26. Bolzan LC. Ajuste fiscal e o Sistema Único de Saúde na gestão estadual do Rio Grande do Sul: a política de saúde esvaziada pela ideologia neoliberal. 2010. Disponível em: <http://www.arca.fiocruz.br/handle/icict/13317>. Acesso em: 11 ago. 2017.

27. Brasil. Presidência da República. Casa Civil. Subchefia para Assuntos Jurídicos. Lei Complementar n 141, de 13 de janeiro de 2012. Regulamenta o § $3 \underline{\text { o }}$ do art. 198 da Constituição Federal para dispor sobre os valores mínimos a serem aplicados anualmente pela União, Estados, Distrito Federal e Municípios em ações e serviços públicos de saúde; estabelece os critérios de rateio dos recursos de transferências para a saúde e as normas de fiscalização, avaliação e controle das despesas com saúde nas 3 (três) esferas de governo; revoga dispositivos das Leis nos 8.080, de 19 de setembro de 1990, e 8.689, de 27 de julho de 1993; e dá outras providências. Brasília: 2012. Disponível em: http://www.planalto.gov.br/ccivil_03/leis/lcp/lcp141.htm Acesso em: 02 fev 2018.

28. Brasil. Conselho Nacional de Secretários de Saúde. Para entender a gestão do SUS / Conselho Nacional de Secretários de Saúde. - Brasília: CONASS. 248 p., 2003. Disponível em:

http://bvsms.saude.gov.br/bvs/publicacoes/para_entender_gestao.pdf Acesso em: 15 fev 2018.

29. Pinto KA, Melo CMM. A prática da enfermeira em auditoria em saúde. Rev Esc Enferm USP, v. 44, n.3, p. 671-678, 2010. Disponível em:

http://www.scielo.br/pdf/reeusp/v44n3/17.pdf Acesso em: 16 fev 2018.

30.

31. . Decreto Federal n. 7797 de 30 de agosto de 2012.

Disponível em: www.planalto.gov.br/ccivil_03/_Ato2011./Decreto/D7797.htm>. Acesso: 27/11/2017.

32. Melo MB; Vaitsman J. Auditoria e Avaliação no Sistema Único de Saúde. 2008. Disponível em: 
$<$ http://produtos.seade.gov.br/produtos/spp/v22n01/v22n01_11.pdf>. Acesso em: 23 jul. 2017.

33. Pimentel LR. O trabalho do auditor do SUS: facilidades, dificuldades, avanços e desafios. Revista Sul Americana de Auditoria em Saúde, v.1, n.2; p.241-284. 10, 2008.

34. Aleluia ÍRS. Principais dificuldades encontradas pelos auditores do Sistema Único de Saúde nos serviços de fisioterapia do Estado da Bahia [monografia de especialização]. Salvador: Universidade Estácio de Sá; 2012.

Recebido: 22 de fevereiro de 2018. Publicado: xx

Correspondência: Daniela Copetti Santos. E-mail:

danielacopetti@yahoo.com.br

Conflito de Interesses: os autores declararam não haver conflito de interesses.

(C) This is an Open Access article distributed under the terms of the Creative Commons Attribution License, which permits unrestricted use, distribution, and reproduction in any medium, provided the original work is properly cited 